\title{
Beyond Clotting: A Role of Platelets in CNS Repair?
}

\author{
Francisco J. Rivera ${ }^{1,2 *}$, Ilias Kazanis ${ }^{3,4}$, Cedric Ghevaert ${ }^{5,6}$ and Ludwig Aigner ${ }^{1,2}$ \\ ${ }^{1}$ Institute of Molecular Regenerative Medicine, Paracelsus Medical University Salzburg, Salzburg, Austria, ${ }^{2}$ Spinal Cord Injury \\ and Tissue Regeneration Center Salzburg, Paracelsus Medical University Salzburg, Salzburg, Austria, ${ }^{3}$ Department of Clinical \\ Neuroscience, Wellcome Trust-Medical Research Council Cambridge Stem Cell Institute, University of Cambridge, \\ Cambridge, UK, ${ }^{4}$ Department of Biology, University of Patras, Patras, Greece, ${ }^{5}$ Department of Haematology, University of \\ Cambridge, Cambridge, UK, ${ }^{6}$ National Health Service Blood and Transplant, Cambridge, UK
}

Keywords: haemostasis, inflammation, angiogenesis, stroke, demyelination, neural stem/progenitor cells, CNS regeneration

\section{"NON-CANONIC" ROLES OF PLATELETS: INFLAMMATION, ANGIOGENESIS AND TISSUE REGENERATION}

Platelets are small, oval, circulating, anucleate cells that upon endothelial damage form a haemostatic plug and stop blood leakage. Circulating platelets derive from bone-marrow-resident megakaryocytes that daily produce and release approximately 100 billions of new platelets into the blood stream (Kaushansky, 2006; Semple et al., 2011). During haemostasis, tethering platelets adhere to the vascular injury through the interaction between their glycoprotein (GP) Ib/V/IX receptor complex and GP VI/GP Ia with the von Willebrand factor (vWF) and collagen provided by the lesioned environment, respectively. Adherent platelets aggregate and secrete platelet activation mediators, such as Thromboxane A2 (TXA2) and adenosine diphosphate (ADP). After activation, the platelets membrane surface becomes procoagulant enhancing the coagulation cascade ending in the formation and stabilization of the haemostatic plug and arresting blood leakage.

OPEN ACCESS

Edited by:

Jose Manuel Garcia-Verdugo, University of Valencia, Spain

Reviewed by:

Yaohui Tang,

Stanford University, USA

*Correspondence:

Francisco J. Rivera

francisco.rivera@pmu.ac.at

Received: 28 September 2015 Accepted: 21 December 2015 Published: 20 January 2016

Citation:

Rivera FJ, Kazanis I, Ghevaert C and Aigner L (2016) Beyond Clotting: A Role of Platelets in CNS Repair?

Front. Cell. Neurosci. 9:511. doi: 10.3389/fncel.2015.00511

Platelet function is not restricted to haemostasis, as platelets also have inflammatory, angiogenic, and tissue repair properties (Nurden, 2011). Within their storage compartments ( $\alpha$-granules and dense granules), platelets store a plethora of bioactive molecules that, under specific circumstances, are secreted to the extracellular space targeting other cell types. Platelets-derived molecules include proteins such as chemokines, cytokines, and growth factors, as well as RNAs and microparticles (Brill et al., 2005; Chen et al., 2012; Lohmann et al., 2012; Schallmoser and Strunk, 2013; Warnke et al., 2013). Platelets granules contain several pro-inflammatory and anti-inflammatory molecules that contribute to immunity. In fact, platelets react against pathogens and regulate immune cells function (reviewed in Semple et al., 2011). For example, during inflammation, GPIb $\alpha$, and P-selectin located at the surface of platelets interact with PSGL-1 and Mac-1 on monocytes/macrophages inducing their recruitment and activation (reviwed in Gawaz et al., 2005). Also, CD154 in activated platelets (Henn et al., 1998) binds to CD40 on endothelial cells (ECs) inducing the expression of cell adhesion molecules (i.e., VCAM1, ICAM1) and the endothelial release of CC-chemokine ligand 2 (CCL2) promoting the leukocyte recruitment to inflammatory sites (Andre et al., 2002). Moreover, CD154 supports B cell differentiation (Elzey et al., 2003; Von Hundelshausen and Weber, 2007) and platelet-secreted transforming growth factor beta (TGF- $\beta$ ) controls $\mathrm{T}_{\text {reg }}$ cell differentiation (Tran, 2012) indicating that the contribution of platelets to immunity is not restricted to the innate system but also involves adaptive response.

Platelets apparently also shape angiogenesis, which is a complex process that consists in the formation/sprouting of new capillaries from preexisting vessels. Platelets have a dual role. 
First, they stimulate ECs proliferation and can promote capillary formation (Pipili-Synetos et al., 1998). Indeed, $\alpha$-granules contain several pro-angiogenic molecules that are secreted upon the activation of platelets, such as vascular endothelial growth factor (VEGF), platelet-derived growth factor (PDGF), TGF$\beta$, basic fibroblast growth factor (bFGF), epidermal growth factor (EGF), sphingosine-1-phosphate (S1P), etc (Kaplan et al., 1979; Heldin et al., 1981; Nakamura et al., 1985; Folkman and Klagsbrun, 1987; Ben-Ezra et al., 1990; Mohle et al., 1997; English et al., 2000; Jonnalagadda et al., 2014). Second, platelets are required to avoid leakage from angiogenic vessels and their absence inhibits the formation of new vessels in vivo (Kisucka et al., 2006).

Haemostasis, inflammation and angiogenesis are essential processes for tissue repair; thus, platelets are critically involved in many mechanisms that operate along the healing process (reviewed in Gurtner et al., 2008; Gawaz and Vogel, 2013). Upon tissue damage provoked by trauma or local ischemia, circulating platelets accumulate and become activated at the lesion site releasing their bioactive molecules into the damaged microenvironment and contributing to tissue repair and regeneration. For instance, stromal cell-derived factor-1 (SDF-1), hepatocyte growth factor (HGF), PDGF, serotonin, ADP, and platelets-derived microparticles regulate recruitment, proliferation, survival, and differentiation not only of immune cells (neutrophils, monocytes) necessary for the local inflammatory and the phagocytic responses, but also of cells that directly repair the lesion such as fibroblast, smooth muscle cells and tissue-specific progenitor cells (Nakamura et al., 1986; Crowley et al., 1994; Stellos et al., 2008, 2010; Mazzucco et al., 2010).

\section{PLATELETS INFLUENCE CNS INFLAMMATION: IMPACT ON REPAIR?}

Regardless of its immune privileged condition and the presence of the blood-brain-barrier (BBB), the CNS is not free from the action of platelets, particularly, in response to injury. As expected, after their adherence to endothelial cells, platelets activate, and recruit leukocytes into the damaged CNS tissue (Simon, 2012; Langer and Chavakis, 2013), thus, platelets interact with different cells in the neurovascular niche including neurons, glial cells, endothelial cells, pericytes, and other bloodderived cells (Hayon et al., 2013; Sotnikov et al., 2013). This particular feature confers platelets a substantial role in CNS inflammation in different pathological scenarios. After stroke, platelets adhere to the endothelium and get activated provoking further thrombo-inflammatory events exaggerating infarct development (Kleinschnitz et al., 2007; Nieswandt et al., 2011). In Alzheimer's disease (AD) the BBB is partially leaky and vascular inflammation occurs (Sardi et al., 2011). Interestingly, platelets might be contributing to the propagation of $\mathrm{AD}$ as they carry amyloid precursor protein and the amyloid beta, two peptides that are found around vessels in $\mathrm{AD}$ patients that constitute one of the molecular mechanisms for $\mathrm{AD}$ pathogenesis (Skovronsky et al., 2001; Catricala et al., 2012).
In multiple sclerosis (MS), an autoimmune CNS demyelinating disease, platelets also seem to be involved to the pathology since they have been found in human chronic active MS lesions (Lock et al., 2002; Langer et al., 2012; Steinman, 2012). In an animal model for MS, platelets promote leukocyte infiltration as well as CNS inflammation (Lock et al., 2002; Langer et al., 2012). Therefore, platelets contribute to neuroinflammation and an altered platelet functions may lead to pathological conditions.

Besides their role in pathogenesis, platelets might also be involved in the regulation of regenerative processes by interacting with CNS stem/progenitor cells. Adult neural stem cells (NSCs) are undifferentiated self-renewing multipotent cells that reside in the subgranular zone (SGZ) in the dentate gyrus of the hippocampus and in the subventricular zone (SVZ) of the wall of the lateral ventricles (Altman, 1965; Gage, 2000; AlvarezBuylla and Garcia-Verdugo, 2002). Oligodendrocyte progenitor cells (OPCs) represent the major cellular source for remyelinating oligodendrocytes and are widely spread throughout the CNS (Ffrench-Constant and Raff, 1986; Woodruff and Franklin, 1999; Franklin and Ffrench-Constant, 2008). Interestingly, NSCs and OPCs drive CNS repair in response to stroke or to MS-associated demyelination (Arvidsson et al., 2002; Franklin, 2002; Kokaia and Lindvall, 2003; Gonzalez-Perez et al., 2009). While neuroinflammation was mainly considered to be an aggravating factor, several recent studies have revealed a supportive role in CNS repair (Patel et al., 2010; Jaerve and Muller, 2012; Miron and Franklin, 2014). For example, the very complex process of remyelination (Franklin and Ffrench-Constant, 2008; Rivera et al., 2010) involves a crucial inflammatory stage that precedes regeneration and occurs acutely after myelin damage. This innate immune response is, at least partially, mediated by blood-recruited macrophages and CNS-resident microglial cells. During remyelination, circulating monocytes/macrophages are recruited by chemotaxis (Charo and Ransohoff, 2006; Ruckh et al., 2012) and, depending on their inflammatory state, exert the following functional roles: (i) they are responsible for the removal (clearance) of myelin debris [which is a potent inhibitor of OPC differentiation (Kotter et al., 2006; Baer et al., 2009)] through phagocytosis, and (ii) they secrete cytokines, growth- and neurotrophic factors that stimulate OPC responses to demyelination (Setzu et al., 2006; Zhao et al., 2006; Ruckh et al., 2012; Miron et al., 2013). A regulation of macrophage recruitment and activity is essential to couple inflammation and regeneration during CNS myelin repair (Miron and Franklin, 2014). However, the cellular and molecular cues that regulate these events are still unknown. As previously mentioned, platelets promote the endothelial secretion of chemokines known to recruit circulating monocytes/macrophages (Gawaz et al., 1998, 2000). Furthermore, through the secretion of PDGF and platelet factor 4 (PF-4), activated platelets directly promote the recruitment of monocytes and modulate their activity (Deuel et al., 1982; Brandt et al., 2000; Fricke et al., 2004). Thus, it can be hypothesized that circulating platelets might influence macrophage/microglia recruitment and activity thereby linking neuroinflammation to CNS repair. 


\section{PLATELETS MODULATE CNS-RESIDENT STEM/PROGENITOR CELL FUNCTION: IMPACT ON REPAIR?}

Supporting the previous hypothesis, a series of findings suggest that platelets directly exert CNS-regenerative activities and might contribute to neuroregeneration (see Table 1). Recently we reported that upon demyelination in the corpus callosum (CC), platelets specifically accumulate within the ipsilateral SVZ vasculature, a process associated with an enhanced survival of SVZ-resident NSCs (Kazanis et al., 2015). Importantly, we found that a mechanical non-demyelinating lesion within the $\mathrm{CC}$ is not enough to induce such accumulation of platelets in the SVZ vasculature, indicating that cellular degeneration is required for such an effect. Considering that SVZ-derived NSCs contribute to remyelination in the CC (Jablonska et al., 2010; Xing et al., 2014), these findings suggest that platelets might play a role in controlling the NSCs pool available for CNS repair. The mechanisms that mediate the very specific accumulation of platelets in the SVZ vasculature far from the lesion site, and that promote NSCs survival are not known. However, platelets derived molecules might be involved as in the same study we found that platelet lysate (PL) protects proliferating NSCs from apoptosis (Kazanis et al., 2015). Furthermore, it has been previously suggested that activated platelets contribute to recovery after brain injury (Hayon et al., 2012c). For example, it has been shown in an animal model for stroke that infused platelets derived microparticles (PMP) increased cell proliferation, neurogenesis and angiogenesis at the infarct boundary zone leading to improvements in behavioral outcomes (Hayon et al., 2012a). In addition to this, a different study showed that PMP promotes NSCs survival and increased their differentiation potential to glia and neurons (Hayon et al., 2012b). Also, upon intracerebroventricular administration of PL into an experimental model of stroke resulted in a significant increase in angiogenesis and in the number of proliferating SVZ-resident NSCs (Hayon et al., 2013). Besides these findings, several platelets derived molecules influence CNS progenitor function (see Table 1). For instance, the dense granules of platelets contain serotonin (White, 1968), which is known to control NSCs activity and adult neurogenesis (Brezun and Daszuta, 1999; Banasr et al., 2004; Goto et al., 2016). The effect of platelets derived molecules might not only target NSCs but also OPCs during remyelination. For instance, platelets' $\alpha$ granules contain large quantities of PDGF and bFGF (Lohmann et al., 2012; Schallmoser and Strunk, 2013), factors that are known to promote OPCs survival, proliferation, and recruitment (Woodruff et al., 2004; Murtie et al., 2005; Zhou et al., 2006). Moreover, upon activation, platelets' $\alpha$-granules secrete S1P (English et al., 2000; Jonnalagadda et al., 2014), a molecule, that is known to modulate OPCs survival, proliferation, and differentiation (Jung et al., 2007). In summary, platelets react to injury and secrete a plethora of bioactive molecules that might directly influence NSCs and OPCs function, probably, modulating CNS repair. This hypothesis could be evaluated by studying neuroregeneration in animal models that display platelet deficiencies (number and/or function). Also, by exploring gene expression databases complemented with proteomics data, further studies could identify molecules contained in platelets that may influence $\mathrm{CNS}$ repair.

\section{FINAL REMARKS}

There is accumulating evidence that the role of platelets is not restricted to haemostasis, but it also involves the regulation of inflammation, angiogenesis and tissue repair. The CNS contains NSCs and OPCs that contribute to cellular turnover and CNS repair. In light of the accumulating evidence that associates

TABLE 1 | Evidences suggesting possible direct contribution of platelets in CNS repair.

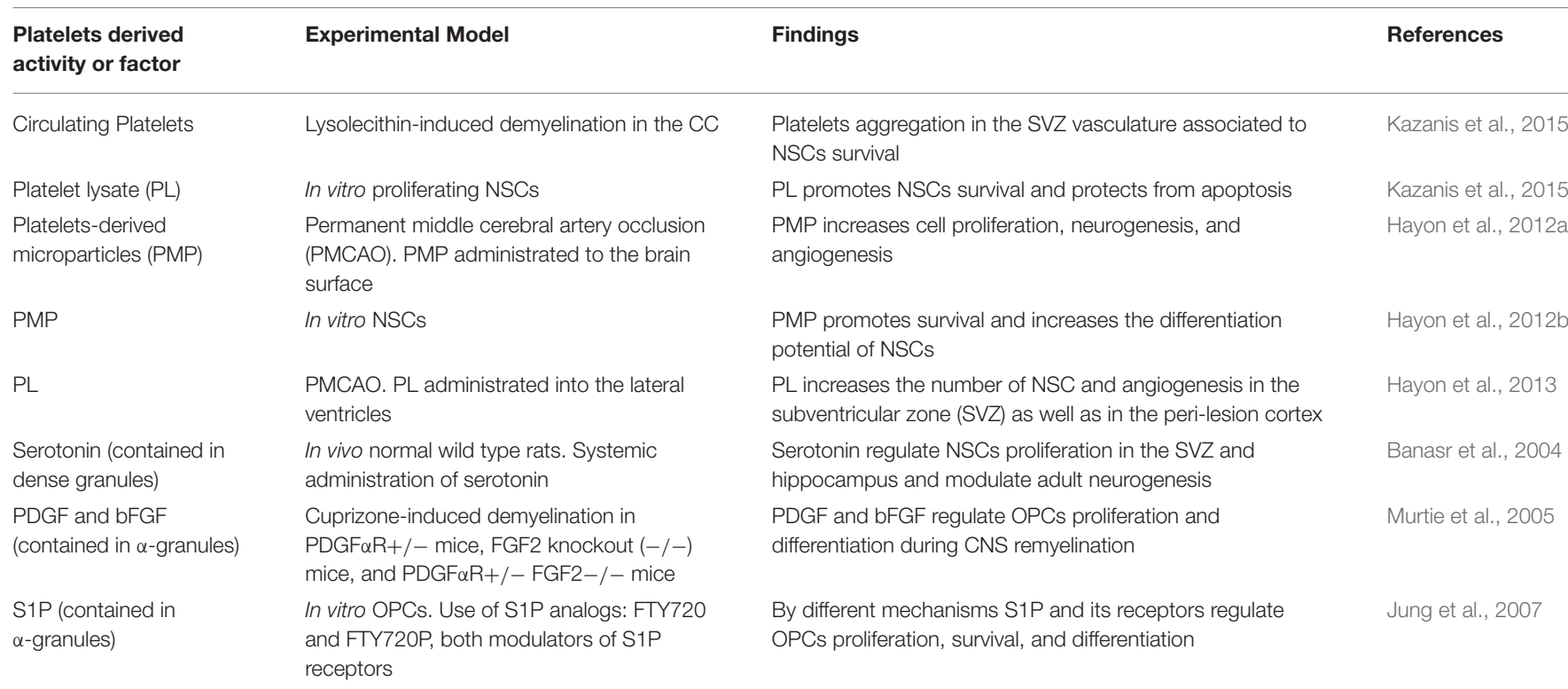


platelets to neuroinflammation, especially under pathological conditions, their potential role in CNS repair has to be further investigated. Recent findings indicate that neuroinflammation is also relevant for CNS repair as it contributes to debris clearance and controls CNS-resident stem/progenitor cells function, suggesting a potential role for platelets by linking inflammation to regeneration. This hypothesis is supported by the facts that circulating platelets react to CNS injury and accumulate within the adult stem cell niche and that activated platelets release a plethora of bioactive molecules that not only regulate immune cells activity but also directly modulates NSC and OPC respond to injury. It is, therefore, likely that platelets might modulate CNS repair. Prospectively, this specific lesion-induced accumulation of circulating platelets at sites of tissue damage, inflammation, and even stem/progenitor cell activity (as in Kazanis et al., 2015) opens the possibility to use genetically manipulated platelets or manufactured platelet-like particles (Risitano et al., 2012; Brown et al., 2014) when aiming for the delivery of specific molecules directly to targeted areas.

\section{REFERENCES}

Altman, J. (1965). Autoradiographic and Histological Evidence of Postnatal Hippocampal Neurogenesis in Rats. J. Comp. Neurol. 124, 17. doi: $10.1002 /$ cne. 901240303

Alvarez-Buylla, A., and Garcia-Verdugo, J. M. (2002). Neurogenesis in adult subventricular zone. J. Neurosci. 22, 629-634. Available online at: $\quad$ http://www.jneurosci.org/content/22/3/629.short?sid=fbdb27ec-65354f73-bb06-d948ca23c506

Andre, P., Nannizzi-Alaimo, L., Prasad, S. K., and Phillips, D. R. (2002). Plateletderived CD40L: the switch-hitting player of cardiovascular disease. Circulation 106, 896-899. doi: 10.1161/01.CIR.0000028962.04520.01

Arvidsson, A., Collin, T., Kirik, D., Kokaia, Z., and Lindvall, O. (2002). Neuronal replacement from endogenous precursors in the adult brain after stroke. Nat. Med. 8, 963-970. doi: 10.1038/nm747

Baer, A. S., Syed, Y. A., Kang, S. U., Mitteregger, D., Vig, R., Ffrench-Constant, C., et al. (2009). Myelin-mediated inhibition of oligodendrocyte precursor differentiation can be overcome by pharmacological modulation of Fyn-RhoA and protein kinase C signalling. Brain 132, 465-481. doi: 10.1093/brain/ awn334

Banasr, M., Hery, M., Printemps, R., and Daszuta, A. (2004). Serotonininduced increases in adult cell proliferation and neurogenesis are mediated through different and common 5-HT receptor subtypes in the dentate gyrus and the subventricular zone. Neuropsychopharmacology 29, 450-460. doi: 10.1038/sj.npp.1300320

Ben-Ezra, J., Sheibani, K., Hwang, D. L., and Lev-Ran, A. (1990). Megakaryocyte synthesis is the source of epidermal growth factor in human platelets. Am. J. Pathol. 137, 755-759.

Brandt, E., Ludwig, A., Petersen, F., and Flad, H. D. (2000). Platelet-derived CXC chemokines: old players in new games. Immunol. Rev. 177, 204-216. doi: 10.1034/j.1600-065X.2000.17705.x

Brezun, J. M., and Daszuta, A. (1999). Depletion in serotonin decreases neurogenesis in the dentate gyrus and the subventricular zone of adult rats. Neuroscience 89, 999-1002. doi: 10.1016/S0306-4522(98)00693-9

Brill, A., Dashevsky, O., Rivo, J., Gozal, Y., and Varon, D. (2005). Plateletderived microparticles induce angiogenesis and stimulate post-ischemic revascularization. Cardiovasc. Res. 67, 30-38. doi: 10.1016/j.cardiores.2005. 04.007

Brown, A. C., Stabenfeldt, S. E., Ahn, B., Hannan, R. T., Dhada, K. S., Herman, E. S., et al. (2014). Ultrasoft microgels displaying emergent platelet-like behaviours. Nat. Mater. 13, 1108-1114. doi: 10.1038/nmat4066

\section{AUTHOR CONTRIBUTIONS}

FR wrote the manuscript. IK, CG, and LA critically reviewed the manuscript. All authors read and approved the final version of the manuscript.

\section{ACKNOWLEDGMENTS}

This work was supported by the State Government of Salzburg, Austria, (Stifungsprofessur, and 20204-WISS/80/199-2014), through funding from the European Union's Seventh Framework Program (FP7/2007-2013) under grant agreements $n^{\circ}$ HEALTHF2-2011-278850 (INMiND), $\mathrm{n}^{\circ}$ HEALTH-F2-2011-279288 (IDEA), $\mathrm{n}^{\circ}$ FP7-REGPOT-316120 (GlowBrain), the Austrian Science Fund FWF Special Research Program (SFB) F44 (F4413B23) "Cell Signaling in Chronic CNS Disorders," by the research funds from the Paracelsus Medical University PMU-FFF (LongTerm Fellowship L-12/01/001-RIV to FR and Stand Alone grant 2058).

Catricala, S., Torti, M., and Ricevuti, G. (2012). Alzheimer disease and platelets: how's that relevant. Immun. Ageing 9:20. doi: 10.1186/1742-4933-9-20

Charo, I. F., and Ransohoff, R. M. (2006). The many roles of chemokines and chemokine receptors in inflammation. N. Engl. J. Med. 354, 610-621. doi: 10.1056/NEJMra052723

Chen, B., Sun, H. H., Wang, H. G., Kong, H., Chen, F. M., and Yu, Q. (2012). The effects of human platelet lysate on dental pulp stem cells derived from impacted human third molars. Biomaterials 33, 5023-5035. doi: 10.1016/j.biomaterials.2012.03.057

Crowley, S. T., Dempsey, E. C., Horwitz, K. B., and Horwitz, L. D. (1994). Plateletinduced vascular smooth muscle cell proliferation is modulated by the growth amplification factors serotonin and adenosine diphosphate. Circulation 90, 1908-1918. doi: 10.1161/01.CIR.90.4.1908

Deuel, T. F., Senior, R. M., Huang, J. S., and Griffin, G. L. (1982). Chemotaxis of monocytes and neutrophils to platelet-derived growth factor. J. Clin. Invest. 69, 1046-1049. doi: 10.1172/JCI110509

Elzey, B. D., Tian, J., Jensen, R. J., Swanson, A. K., Lees, J. R., Lentz, S. R., et al. (2003). Platelet-mediated modulation of adaptive immunity. A communication link between innate and adaptive immune compartments. Immunity 19, 9-19. doi: 10.1016/S1074-7613(03)00177-8

English, D., Welch, Z., Kovala, A. T., Harvey, K., Volpert, O. V., Brindley, D. N., et al. (2000). Sphingosine 1-phosphate released from platelets during clotting accounts for the potent endothelial cell chemotactic activity of blood serum and provides a novel link between hemostasis and angiogenesis. FASEB J. 14, 2255-2265. doi: 10.1096/fj.00-0134com

Ffrench-Constant, C., and Raff, M. C. (1986). The oligodendrocyte-type-2 astrocyte cell lineage is specialized for myelination. Nature 323, 335-338. doi: $10.1038 / 323335 \mathrm{a} 0$

Folkman, J., and Klagsbrun, M. (1987). Angiogenic factors. Science 235, 442-447. doi: $10.1126 /$ science. 2432664

Franklin, R. J. (2002). Why does remyelination fail in multiple sclerosis? Nat. Rev. Neurosci. 3, 705-714. doi: 10.1038/nrn917

Franklin, R. J., and Ffrench-Constant, C. (2008). Remyelination in the CNS: from biology to therapy. Nat. Rev. Neurosci. 9, 839-855. doi: 10.1038/ nrn 2480

Fricke, I., Mitchell, D., Petersen, F., Bohle, A., Bulfone-Paus, S., and Brandau, S. (2004). Platelet factor 4 in conjunction with IL-4 directs differentiation of human monocytes into specialized antigen-presenting cells. FASEB J. 18, 1588-1590. doi: 10.1096/fj.03-1435fje

Gage, F. H. (2000). Mammalian neural stem cells. Science 287, 1433-1438. doi: $10.1126 /$ science. 287.5457 .1433 
Gawaz, M., Brand, K., Dickfeld, T., Pogatsa-Murray, G., Page, S., Bogner, C., et al. (2000). Platelets induce alterations of chemotactic and adhesive properties of endothelial cells mediated through an interleukin-1-dependent mechanism. Implications for atherogenesis. Atherosclerosis 148, 75-85. doi: 10.1016/S00219150(99)00241-5

Gawaz, M., Langer, H., and May, A. E. (2005). Platelets in inflammation and atherogenesis. J. Clin. Invest. 115, 3378-3384. doi: 10.1172/JCI27196

Gawaz, M., Neumann, F. J., Dickfeld, T., Koch, W., Laugwitz, K. L., Adelsberger, H., et al. (1998). Activated platelets induce monocyte chemotactic protein1 secretion and surface expression of intercellular adhesion molecule- 1 on endothelial cells. Circulation 98, 1164-1171. doi: 10.1161/01.CIR.98.12.1164

Gawaz, M., and Vogel, S. (2013). Platelets in tissue repair: control of apoptosis and interactions with regenerative cells. Blood 122, 2550-2554. doi: 10.1182/blood2013-05-468694

Gonzalez-Perez, O., Romero-Rodriguez, R., Soriano-Navarro, M., GarciaVerdugo, J. M., and Alvarez-Buylla, A. (2009). Epidermal growth factor induces the progeny of subventricular zone type B cells to migrate and differentiate into oligodendrocytes. Stem Cells 27, 2032-2043. doi: 10.1002/ stem.119

Goto, K., Kawahara, I., Inada, H., Misawa, H., Kuniyasu, H., Nabekura, J., et al. (2016). Activation of 5-HT4 receptors facilitates neurogenesis from transplanted neural stem cells in the anastomotic ileum. J. Physiol. Sci. 66, 67-76. doi: 10.1007/s12576-015-0396-1

Gurtner, G. C., Werner, S., Barrandon, Y., and Longaker, M. T. (2008). Wound repair and regeneration. Nature 453, 314-321. doi: 10.1038/nature07039

Hayon, Y., Dashevsky, O., Shai, E., Brill, A., Varon, D., and Leker, R. R. (2012a). Platelet microparticles induce angiogenesis and neurogenesis after cerebral ischemia. Curr. Neurovasc. Res. 9, 185-192. doi: 10.2174/156720212801619018

Hayon, Y., Dashevsky, O., Shai, E., Varon, D., and Leker, R. R. (2012b). Platelet microparticles promote neural stem cell proliferation, survival and differentiation. J. Mol. Neurosci. 47, 659-665. doi: 10.1007/s12031-012-9711-y

Hayon, Y., Dashevsky, O., Shai, E., Varon, D., and Leker, R. R. (2013). Platelet lysates stimulate angiogenesis, neurogenesis and neuroprotection after stroke. Thromb. Haemost. 110, 323-330. doi: 10.1160/TH12-11-0875

Hayon, Y., Shai, E., Varon, D., and Leker, R. R. (2012c). The role of platelets and their microparticles in rehabilitation of ischemic brain tissue. CNS Neurol. Disord. Drug Targets 11, 921-925. doi: 10.2174/1871527311201070921

Heldin, C. H., Westermark, B., and Wasteson, A. (1981). Platelet-derived growth factor. Isolation by a large-scale procedure and analysis of subunit composition. Biochem. J. 193, 907-913. doi: 10.1042/bj1930907

Henn, V., Slupsky, J. R., Grafe, M., Anagnostopoulos, I., Forster, R., MullerBerghaus, G., et al. (1998). CD40 ligand on activated platelets triggers an inflammatory reaction of endothelial cells. Nature 391, 591-594. doi: $10.1038 / 35393$

Jablonska, B., Aguirre, A., Raymond, M., Szabo, G., Kitabatake, Y., Sailor, K. A., et al. (2010). Chordin-induced lineage plasticity of adult SVZ neuroblasts after demyelination. Nat. Neurosci. 13, 541-550. doi: 10.1038/nn.2536

Jaerve, A., and Muller, H. W. (2012). Chemokines in CNS injury and repair. Cell Tissue Res. 349, 229-248. doi: 10.1007/s00441-012-1427-3

Jonnalagadda, D., Sunkara, M., Morris, A. J., and Whiteheart, S. W. (2014). Granule-mediated release of sphingosine-1-phosphate by activated platelets. Biochim. Biophys. Acta 1841, 1581-1589. doi: 10.1016/j.bbalip.2014.08.013

Jung, C. G., Kim, H. J., Miron, V. E., Cook, S., Kennedy, T. E., Foster, C. A., et al. (2007). Functional consequences of S1P receptor modulation in rat oligodendroglial lineage cells. Glia 55, 1656-1667. doi: 10.1002/glia.20576

Kaplan, D. R., Chao, F. C., Stiles, C. D., Antoniades, H. N., and Scher, C. D. (1979). Platelet alpha granules contain a growth factor for fibroblasts. Blood $53,1043-1052$

Kaushansky, K. (2006). Lineage-specific hematopoietic growth factors. N. Engl. J. Med. 354, 2034-2045. doi: 10.1056/NEJMra052706

Kazanis, I., Feichtner, M., Lange, S., Rotheneichner, P., Hainzl, S., Oller, M., et al. (2015). Lesion-induced accumulation of platelets promotes survival of adult neural stem / progenitor cells. Exp. Neurol. 269, 75-89. doi: 10.1016/j.expneurol.2015.03.018

Kisucka, J., Butterfield, C. E., Duda, D. G., Eichenberger, S. C., Saffaripour, S., Ware, J., et al. (2006). Platelets and platelet adhesion support angiogenesis while preventing excessive hemorrhage. Proc. Natl. Acad. Sci. U.S.A. 103, 855-860. doi: $10.1073 /$ pnas. 0510412103
Kleinschnitz, C., Pozgajova, M., Pham, M., Bendszus, M., Nieswandt, B., and Stoll, G. (2007). Targeting platelets in acute experimental stroke: impact of glycoprotein Ib, VI, and IIb/IIIa blockade on infarct size, functional outcome, and intracranial bleeding. Circulation 115, 2323-2330. doi: 10.1161/CIRCULATIONAHA.107.691279

Kokaia, Z., and Lindvall, O. (2003). Neurogenesis after ischaemic brain insults. Curr. Opin. Neurobiol. 13, 127-132. doi: 10.1016/S0959-4388(03)00017-5

Kotter, M. R., Li, W. W., Zhao, C., and Franklin, R. J. (2006). Myelin impairs CNS remyelination by inhibiting oligodendrocyte precursor cell differentiation. J. Neurosci. 26, 328-332. doi: 10.1523/JNEUROSCI.2615-05.2006

Langer, H. F., and Chavakis, T. (2013). Platelets and neurovascular inflammation. Thromb. Haemost. 110, 888-893. doi: 10.1160/TH13-02-0096

Langer, H. F., Choi, E. Y., Zhou, H., Schleicher, R., Chung, K. J., Tang, Z., et al. (2012). Platelets contribute to the pathogenesis of experimental autoimmune encephalomyelitis. Circ. Res. 110, 1202-1210. doi: 10.1161/CIRCRESAHA.111.256370

Lock, C., Hermans, G., Pedotti, R., Brendolan, A., Schadt, E., Garren, H., et al. (2002). Gene-microarray analysis of multiple sclerosis lesions yields new targets validated in autoimmune encephalomyelitis. Nat. Med. 8, 500-508. doi: 10.1038/nm0502-500

Lohmann, M., Walenda, G., Hemeda, H., Joussen, S., Drescher, W., Jockenhoevel, S., et al. (2012). Donor age of human platelet lysate affects proliferation and differentiation of mesenchymal stem cells. PLOS ONE 7:e37839. doi: 10.1371/journal.pone.0037839

Mazzucco, L., Borzini, P., and Gope, R. (2010). Platelet-derived factors involved in tissue repair-from signal to function. Transfus. Med. Rev. 24, 218-234. doi: 10.1016/j.tmrv.2010.03.004

Miron, V. E., Boyd, A., Zhao, J. W., Yuen, T. J., Ruckh, J. M., Shadrach, J. L., et al. (2013). M2 microglia and macrophages drive oligodendrocyte differentiation during CNS remyelination. Nat. Neurosci. 16, 1211-1218. doi: 10.1038/nn.3469

Miron, V. E., and Franklin, R. J. (2014). Macrophages and CNS remyelination. J. Neurochem. 130, 165-171. doi: 10.1111/jnc.12705

Mohle, R., Green, D., Moore, M. A., Nachman, R. L., and Rafii, S. (1997) Constitutive production and thrombin-induced release of vascular endothelial growth factor by human megakaryocytes and platelets. Proc. Natl. Acad. Sci. U.S.A. 94, 663-668. doi: 10.1073/pnas.94.2.663

Murtie, J. C., Zhou, Y. X., Le, T. Q., Vana, A. C., and Armstrong, R. C. (2005). PDGF and FGF2 pathways regulate distinct oligodendrocyte lineage responses in experimental demyelination with spontaneous remyelination. Neurobiol. Dis. 19, 171-182. doi: 10.1016/j.nbd.2004.12.006

Nakamura, T., Teramoto, H., and Ichihara, A. (1986). Purification and characterization of a growth factor from rat platelets for mature parenchymal hepatocytes in primary cultures. Proc. Natl. Acad. Sci. U.S.A. 83, 6489-6493. doi: $10.1073 /$ pnas.83.17.6489

Nakamura, T., Tomita, Y., Hirai, R., Yamaoka, K., Kaji, K., and Ichihara, A. (1985). Inhibitory effect of transforming growth factor-beta on DNA synthesis of adult rat hepatocytes in primary culture. Biochem. Biophys. Res. Commun. 133, 1042-1050. doi: 10.1016/0006-291X(85)91241-0

Nieswandt, B., Kleinschnitz, C., and Stoll, G. (2011). Ischaemic stroke: a thrombo-inflammatory disease? J. Physiol. (Lond). 589, 4115-4123. doi: 10.1113/jphysiol.2011.212886

Nurden, A. T. (2011). Platelets, inflammation and tissue regeneration. Thromb. Haemost. 105(Suppl. 1), S13-S33. doi: 10.1160/THS10-11-0720

Patel, J. R., Mccandless, E. E., Dorsey, D., and Klein, R. S. (2010). CXCR4 promotes differentiation of oligodendrocyte progenitors and remyelination. Proc. Natl. Acad. Sci. U.S.A. 107, 11062-11067. doi: 10.1073/pnas.1006301107

Pipili-Synetos, E., Papadimitriou, E., and Maragoudakis, M. E. (1998). Evidence that platelets promote tube formation by endothelial cells on matrigel. $\mathrm{Br}$. J. Pharmacol. 125, 1252-1257. doi: 10.1038/sj.bjp.0702191

Risitano, A., Beaulieu, L. M., Vitseva, O., and Freedman, J. E. (2012). Platelets and platelet-like particles mediate intercellular RNA transfer. Blood 119, 6288-6295. doi: 10.1182/blood-2011-12-396440

Rivera, F. J., Steffenhagen, C., Kremer, D., Kandasamy, M., Sandner, B., CouillardDespres, S., et al. (2010). Deciphering the oligodendrogenic program of neural progenitors: cell intrinsic and extrinsic regulators. Stem Cells Dev. 19, 595-606. doi: $10.1089 / \mathrm{scd} .2009 .0293$

Ruckh, J. M., Zhao, J.-W., Shadrach, J. L., Van wijngaarden, P., Rao, T. N., Wagers, A. J., et al. (2012). Rejuvenation of regeneration in the aging 
central nervous system. Cell Stem Cell 10, 96-103. doi: 10.1016/j.stem.2011. 11.019

Sardi, F., Fassina, L., Venturini, L., Inguscio, M., Guerriero, F., Rolfo, E., et al. (2011). Alzheimer's disease, autoimmunity and inflammation. The good, the bad and the ugly. Autoimmun. Rev. 11, 149-153. doi: 10.1016/j.autrev.2011.09.005

Schallmoser, K., and Strunk, D. (2013). Generation of a pool of human platelet lysate and efficient use in cell culture. Methods Mol. Biol. 946, 349-362. doi: 10.1007/978-1-62703-128-8_22

Semple, J. W., Italiano, J. E. Jr., and Freedman, J. (2011). Platelets and the immune continuum. Nat. Rev. Immunol. 11, 264-274. doi: 10.1038/nri2956

Setzu, A., Lathia, J. D., Zhao, C., Wells, K., Rao, M. S., Ffrench-Constant, C., et al. (2006). Inflammation stimulates myelination by transplanted oligodendrocyte precursor cells. Glia 54, 297-303. doi: 10.1002/glia.20371

Simon, D. I. (2012). Inflammation and vascular injury: basic discovery to drug development. Circ. J. 76, 1811-1818. doi: 10.1253/circj.CJ-12-0801

Skovronsky, D. M., Lee, V. M., and Pratico, D. (2001). Amyloid precursor protein and amyloid beta peptide in human platelets. Role of cyclooxygenase and protein kinase C. J. Biol. Chem. 276, 17036-17043. doi: 10.1074/jbc.M006285200

Sotnikov, I., Veremeyko, T., Starossom, S. C., Barteneva, N., Weiner, H. L., and Ponomarev, E. D. (2013). Platelets recognize brain-specific glycolipid structures, respond to neurovascular damage and promote neuroinflammation. PLoS ONE 8:e58979. doi: 10.1371/journal.pone.0058979

Steinman, L. (2012). The discovery of natalizumab, a potent therapeutic for multiple sclerosis. J. Cell Biol. 199, 413-416. doi: 10.1083/jcb.201207175

Stellos, K., Kopf, S., Paul, A., Marquardt, J. U., Gawaz, M., Huard, J., et al. (2010). Platelets in regeneration. Semin. Thromb. Hemost. 36, 175-184. doi: 10.1055/s-0030-1251502

Stellos, K., Langer, H., Daub, K., Schoenberger, T., Gauss, A., Geisler, T., et al. (2008). Platelet-derived stromal cell-derived factor-1 regulates adhesion and promotes differentiation of human CD34+ cells to endothelial progenitor cells. Circulation 117, 206-215. doi: 10.1161/CIRCULATIONAHA.107.714691

Tran, D. Q. (2012). TGF-beta: the sword, the wand, and the shield of FOXP3(+) regulatory T cells. J. Mol. Cell Biol. 4, 29-37. doi: 10.1093/jmcb/mjr033

Von Hundelshausen, P., and Weber, C. (2007). Platelets as immune cells: bridging inflammation and cardiovascular disease. Circ. Res. 100, 27-40. doi: 10.1161/01.RES.0000252802.25497.b7
Warnke, P. H., Humpe, A., Strunk, D., Stephens, S., Warnke, F., Wiltfang, J., et al. (2013). A clinically-feasible protocol for using human platelet lysate and mesenchymal stem cells in regenerative therapies. J. Craniomaxillofac. Surg. 41, 153-161. doi: 10.1016/j.jcms.2012.07.003

White, J. G. (1968). The dense bodies of human platelets. Origin of serotonin storage particles from platelet granules. Am. J. Pathol. 53, 791-808.

Woodruff, R. H., and Franklin, R. J. (1999). Demyelination and remyelination of the caudal cerebellar peduncle of adult rats following stereotaxic injections of lysolecithin, ethidium bromide, and complement/anti-galactocerebroside: a comparative study. Glia 25, 216-228.

Woodruff, R. H., Fruttiger, M., Richardson, W. D., and Franklin, R. J. M. (2004). Platelet-derived growth factor regulates oligodendrocyte progenitor numbers in adult CNS and their response following CNS demyelination. Mol. Cell. Neurosci. 25, 252-262. doi: 10.1016/j.mcn.2003. 10.014

Xing, Y. L., Roth, P. T., Stratton, J. A., Chuang, B. H., Danne, J., Ellis, S. L., et al. (2014). Adult neural precursor cells from the subventricular zone contribute significantly to oligodendrocyte regeneration and remyelination. J. Neurosci. 34, 14128-14146. doi: 10.1523/JNEUROSCI.3491-13.2014

Zhao, C., Li, W. W., and Franklin, R. J. (2006). Differences in the early inflammatory responses to toxin-induced demyelination are associated with the age-related decline in CNS remyelination. Neurobiol. Aging 27, 1298-1307. doi: 10.1016/j.neurobiolaging.2005.06.008

Zhou, Y. X., Flint, N. C., Murtie, J. C., Le, T. Q., and Armstrong, R. C. (2006). Retroviral lineage analysis of fibroblast growth factor receptor signaling in FGF2 inhibition of oligodendrocyte progenitor differentiation. Glia 54, 578-590. doi: 10.1002/glia.20410

Conflict of Interest Statement: The authors declare that the research was conducted in the absence of any commercial or financial relationships that could be construed as a potential conflict of interest.

Copyright (C) 2016 Rivera, Kazanis, Ghevaert and Aigner. This is an open-access article distributed under the terms of the Creative Commons Attribution License (CC $B Y)$. The use, distribution or reproduction in other forums is permitted, provided the original author(s) or licensor are credited and that the original publication in this journal is cited, in accordance with accepted academic practice. No use, distribution or reproduction is permitted which does not comply with these terms. 